\section{Rasgos inmunohistopatológicos de la esclerosis múltiple y marcadores de la enfermedad}

Del 26 al 27 de marzo de 1997 y con el título "Fronteras de la ciencia", se llevó a cabo en Birmingham, Reino Unido, la Reunión Anual de la Sociedad de Esclerosis Múltiple de Gran Bretaña e Irlanda del Norte, en cuyo transcurso se discutieron diferentes aspectos de tan compleja afección, con particular énfasis en la necesidad de definir sus variados perfiles inmunohistopatológicos y de correlacionarlos con los indicadores paraclínicos y clínicos de la enfermedad. Amor et al. dieron inicio a la reunión con la discusión de la amplia gama de lesiones histológicas, básicamente caracterizadas por desmielinización, infiltración de células mononucleares y destrucción de axonas. Hasta el momento las lesiones más tempranas muestran los rasgos histopatológicos más definidos, aunque sin aparente correlación con la evolución clínica, pero es posible que una observación más prolongada revele alguna asociación entre los distintos tipos de lesiones (activas tempranas, activas tardías o crónicas) y las formas clínicas que adopta la enfermedad (primaria progresiva o intermitente con recaídas y remisiones).

$\mathrm{Si}$ bien la esclerosis múltiple parece vincularse con un mecanismo autoinmunitario, resta por identificar al antígeno responsable. Actualmente se efectúan investigaciones sobre las proteínas clásicas de la mielina y la $\alpha \mathrm{B}$-cristalina, que es el antígeno inmunodominante en las lesiones y que muestra una reacción cruzada con algunos virus, como el de Epstein-Barr.

Por otra parte, se especula que los macrófagos, usualmente involucrados en el proceso inflamatorio, también desempeñarían un papel importante en la remielinización y en la proliferación y migración de los oligodendrocitos durante la restauración y reparación tisulares. Es indudable que la comprobada heterogeneidad genética de la enfermedad y de los pacientes afectados continúa dificultando los estudios poblacionales encaminados a definir los genes involucrados con mayor frecuencia.

Para marcar la evolución de la enfermedad son de enorme valor la imaginería por resonancia magnética, las técnicas que emplean una triple dosis de gadolinio y la transferencia por magnetización, así como otras más recientes, entre ellas la espectrografía por resonancia magnética. Para seguir los marcadores paraclínicos podría resultar útil la determinación de enolasa específica de neuronas, dado que la razón enolasa:albúmina suele estar aumentada. El mayor problema sigue siendo, sin embargo, la ausencia de marcadores paraclínicos y de laboratorio confiables que permitan precisar cuán activa es la enfermedad; de contarse con ellos, se podrían evaluar más fehacientemente los beneficios del tratamiento instituido, sea interferón $\beta$, copolímero 1 o inmunoglobulina endovenosa.

Aunque los rasgos histopatológicos, al igual que los genéticos y clínicos, son heterogéneos en la esclerosis múltiple, pueden llegar a definirse subtipos de lesiones. Si esas variaciones dependieran de diferentes autoantígenos o diferentes factores patógenos, la correlación de los parámetros inmunohistopatológicos con los signos clínicos podría suministrar información útil para diseñar tratamientos dirigidos a prevenir el daño a las axonas y un tratamiento inmunoespecífico. (Amor S, Baker D, Layward L, McCormack K, van Noort JM. Multiple sclerosis: variations on a theme. Immunol Today 1997;18:368-370).

\section{Brote epidémico por transmisión del poxvirus de los monos entre seres humanos}

Aunque se sabe desde hace varias décadas que el poxvirus de los monos puede infectar al hombre, siempre se pensó que la posibilidad era rara, dada la baja frecuencia de la transmisión entre seres humanos. De ahí el estado de alerta ocasionado por la aparición de un mínimo de 92 casos y tres defunciones en la República Democrática del Congo entre febrero de 1996 y febrero de 1997. Según información suministrada por un equipo de trabajo internacional integrado por la OMS y el Ministerio de Salud local, de 89 personas estudiadas, $73 \%$ se contagiaron por contacto con humanos infectados. Este porcentaje, que representa un notable incremento con respecto al 30\% registrado en la misma zona de 1981 a 1986, suscitó gran inquietud. La diseminación entre seres humanos podría haber sido facilitada por la guerra civil en curso, ya que por hambre los campesinos recurrieron a la caza de animales portadores del virus, es decir, monos, ardillas y ratas. Otra posibilidad es que la población haya perdido la protección conferida por una vacunación antivariólica con efecto protector contra la 
viruela de los monos, dada la estrecha relación entre los dos poxvirus causales.

Solo $18 \%$ de los afectados mostraron viejas escaras por vacunación y aun en esos casos es probable que no estuvieran protegidos, porque la inmunidad habría dejado de ser eficaz 5 a 10 años después de la vacunación antivariólica, que en todo el mundo fue suspendida hace dos décadas. La explicación más inquietante -que el poxvirus de los monos hubiera mutado haciéndose más virulento o más transmisible - no ha sido confirmada por el análisis genético de los aislamientos. En todo caso, la posibilidad de que el virus se haya adaptado al hombre es ominosa.

Si bien es cierto que por el momento las actitudes alarmistas no están justificadas, el virólogo Peter Jahrling, del Instituto para la Investigación de Enfermedades Transmisibles del Ejército de los Estados Unidos de América (U.S. Army Medical Research Institute of Infectious Diseases) en Fort Detrick, Maryland, logró convencer a los militares estadounidenses de que se vacunara a las tropas destinadas a la zona afectada. En general, los investigadores se muestran reticentes a instituir un nuevo programa de vacunación antivariólica en la población local por temor a que provoque enfermedad y muerte en un área con una alta tasa de infección por VIH y, consiguientemente, de inmunodepresión. Por el momento la OMS, alerta ante el brote, ha advertido acerca de los riesgos implicados por la retirada de soldados del territorio donde ocurrió el brote y también por el posible desplazamiento hacia él de refugiados procedentes de Ruanda.

Oportunamente, Cohen recuerda que hace casi 4 años se discutieron las ventajas y desventajas de destruir las dos únicas reservas del virus de la viruela que hoy quedan en el mundo: una en Atlanta, Georgia, y la otra en Moscú, Rusia. Para los partidarios de conservarlas y de estudiar el virus para definir sus secuencias genéticas, la aparición del poxvirus de los monos en el hombre será un argumento a favor. La destrucción de las dos reservas del virus de la viruela está proyectada para el 30 de junio de 1999; un mes antes se celebrará la Asamblea Mundial de la Salud que, por sus atribuciones, estaría en condiciones de postergar esa eliminación. (Cohen J. Is an old virus up to new tricks? Science 1997;277:312-313).

\section{La prevención de infecciones perinatales en países en desarrollo}

Muchas intervenciones eficaces para reducir las infecciones perinatales son difíciles de llevar a cabo en países en desarrollo, que es precisamente donde son más necesarias. Ello se debe a numerosos factores, como su alto costo y la necesidad de efectuar pruebas de laboratorio y de hospitalizar a la paciente antes del parto. Se impone, por lo tanto, la consideración de otras opciones.

En casos de transmisión perinatal de VIH, está ampliamente establecida la eficacia del tratamiento de la madre y del recién nacido con zidovudina, pero su carestía impide aplicarlo a grandes sectores de la población de los países en desarrollo. Una posible solución es la administración de un tratamiento abreviado, cuya eficacia está en proceso de investigación. Aunque la lactancia materna parece favorecer la transmisión de la infección, su abandono no se recomienda en lugares donde no hay fuentes seguras, de alimentos sustitutos adecuados, por lo menos durante los primeros 6 meses de vida.

Se acepta que en muchos casos la cesárea reduce el riesgo de infección por VIH, dada la aparente vinculación entre la ruptura de membranas de más de 4 horas de duración y la infección del recién nacido. Si así fuera, correspondería iniciar estudios orientados a modificar la política que favorece la ruptura artificial y prematura de las membranas, que es práctica común en muchos países en desarrollo.

Está comprobado que el tratamiento con antibióticos reduce la tasa de nacimientos prematuros ocasionados por infecciones bacterianas perinatales. Tal es el caso cuando la madre recibe tratamiento por vaginitis; asimismo, la administración de oxitocina a madres con ruptura prematura de membranas puede disminuir las tasas de infección neonatal y la admisión de recién nacidos a unidades de cuidados intensivos.

El tratamiento de mujeres colonizadas por estreptococos del grupo B sigue planteando un problema. La infección suele ser asintomática, las tasas de infección neonatal grave son bajas en relación con el gran número de portadoras, y la recolonización después del tratamiento es fenómeno frecuente. Si bien se ha comprobado que $1 \mathrm{~g}$ de ampicilina endovenosa cada 6 horas durante el parto reduce la incidencia de infección en neonatos, la intervención implica el tamizaje rutinario de mujeres asintomáticas, que además de ser oneroso exige la disponibilidad de un laboratorio adecuado. Una opción promisoria es la limpieza del canal del parto con antibióticos. Taha et al. lograron reducir las tasas de infección y mortalidad perinatales durante el período de 3 meses en que emplearon solución de clorohexidina al 25\% durante el parto. Para Hofmeyr y McIntyre, de la Universidad de Witwatersrand, Sudáfrica, ese hallazgo reviste una enorme importancia para la práctica médica en todas partes $\mathrm{y}$, por tanto, justifica que se lleven a cabo con urgencia ensayos multicéntricos y aleatorios para 
confirmar a mayor escala la eficacia del procedimiento. (Hofmeyr GJ, McIntyre J. Preventing perinatal infections. BMJ 1997;315:199-200).

\section{Variación geográfica de las tasas de mortalidad por síndrome de muerte súbita infantil}

Las tasas de mortalidad por síndrome de muerte súbita infantil (SMSI) varían considerablemente de un país a otro. Son muy bajas en Hong Kong (0,3 defunciones por 1000 habitantes en 1987) y muy altas en Nueva Zelandia (4,4 defunciones por 1000 habitantes en 1988). Sería importante conocer las razones de esas diferencias, pero primero falta llegar a una definición del síndrome, cosa que aún no se ha logrado.

En 1969, Beckwith caracterizó al SMSI como un siniestro inesperado, sin causa demostrable por examen posmortem, en neonatos sin antecedentes de morbilidad. Los resultados del examen histopatológico fueron precisamente los que provocaron mayor desacuerdo en torno a la verdadera importancia del infiltrado inflamatorio presente en los pulmones, el miocardio y el encéfalo. Tampoco había manera de distinguir entre el SMSI y una asfixia accidental o por otras causas. Esas y otras consideraciones llevaron a sucesivas propuestas para la modificación de la definición inicial.

En muchos países se extiende un certificado de defunción por SMSI sin hacerse una autopsia, y aun en aquellos donde esta sí se practica, su frecuencia varía considerablemente. En algunos países se efectúa la autopsia en casi $100 \%$ de los casos de SMSI y en otros, en apenas $50 \%$.

Vege y Rognum investigaron las aparentes discrepancias en la mortalidad por SMSI observadas en los países nórdicos y los cambios que ha sufrido el diagnóstico de SMSI a lo largo del tiempo. Para ello recurrieron a un conjunto de criterios diagnósticos definidos por el Grupo de Patología Nórdica y adoptados por los países escandinavos a partir de 1992, aplicándolos de manera uniforme en un estudio retrospectivo de muertes infantiles inesperadas y súbitas, pero no necesariamente categorizadas como SMSI. Si esos mismos criterios u otros fueran empleados por patólogos de otros países, se podrían aminorar las variaciones en el diagnóstico, aunque sin lograr eliminarlas por completo. Dado que la interpretación de los hallazgos de la autopsia se modifican en virtud de un renovado y mejor conocimiento de la histopatología, los diagnósticos serían solo provisorios y por lo tanto estarían sujetos a una revisión periódica.

La comparación de las tasas de mortalidad de distintos países y en diferentes momentos se ve limitada por la falta de una definición homogénea de SMSI, la ausencia de autopsia en algunos lugares y la interpretación dada a los resultados del examen histopatológico cuando se efectúa. Se podrían superar estas limitaciones parcialmente si se recurriera a la mortalidad total (es decir, por todas las causas posibles), aunque circunscrita al estrecho recorrido de edad correspondiente al del momento del deceso. De ese modo se observa que la proporción de SMSI en Noruega alcanzó un máximo de $56 \%$ entre los 105 y 125 días de vida, período no registrado por las estadísticas oficiales de mortalidad. Sin embargo, esos mismos datos mostraron que la fracción de todas las muertes atribuible a SMSI fue mayor de $40 \%$ desde las 6 hasta las 30 semanas de vida. Ello sugiere que la mortalidad total del primer al quinto mes de edad, que es información fácilmente obtenible, sería tan válida para su estimación como la correspondiente a los 105 a 125 días de vida.

La mortalidad en el grupo de edad de 1-5 meses también difiere considerablemente de un país a otro. En algunos países aumentó en las décadas de 1970 y 1980, para luego disminuir durante los años noventa, lo que significa un incremento real con un descenso subsiguiente de la mortalidad por SMSI. Es posible que esta reducción se haya debido a una menor tendencia a colocar a los niños en posición de decúbito ventral. Actualmente el desafío consiste en identificar los factores responsables de las diferencias de mortalidad que se siguen observando entre diferentes países, ya que ello permitiría idear una intervención adecuada para prevenir el SMSI. (Mitchell EA, Becroft DMO. Comparison of sudden infant death syndrome mortality over time and among countries. Acta Paediat 1997; 86:789-790).

\section{Criterios para el diagnóstico del síndrome de cansancio crónico: sus limitaciones}

Ante la falta de marcadores diagnósticos del síndrome de cansancio crónico (en inglés chronic fatigue syndrome, o CFS), se ha recurrido a criterios de inclusión y exclusión, lo que explica las diferencias observadas en el diagnóstico de ese trastorno en los Estados Unidos de América, el Reino Unido y Australia, por citar algunos ejemplos. Con el fin de homogeneizar conceptos, un panel internacional integrado por representantes de los Centros para el Control y la Prevención de Enfermedades y los Institutos Nacionales de Salud, en los Estados Unidos, y el Grupo de Estudio del Síndrome de Cansancio Crónico, efectuó en 1994 una revisión de los criterios diagnósticos habituales. El panel propuso cuatro criterios mayores (cansancio inexplicable, persistente o intermitente, sin relación con el 
ejercicio y sin la posibilidad de obtener alivio con el descanso, y consiguiente reducción de las actividades ocupacionales, educacionales, sociales o personales) y ocho menores (deterioro de la memoria de corto término o de la capacidad de concentración; dolor de garganta; sensibilidad anormal de ganglios cervicales o axilares; mialgias; poliartralgias sin inflamación; cefalea; sueño no reparador; y malestar de más de 24 horas de duración después del ejercicio). Para establecer el diagnóstico en personas adultas, se deberán satisfacer los cuatro criterios mayores y un mínimo de cuatro de los menores, que deben haber persistido o recurrido durante 6 meses o más. Cuando en octubre de 1996 tuvo lugar en San Francisco, Estados Unidos, la Reunión de la Asociación Americana del Síndrome de Cansancio Crónico (American Association for Chronic Fatigue Syndrome), se planteó la posibilidad de aplicar estos criterios para hacer el diagnóstico en adolescentes, reconociéndose simultáneamente la mayor dificultad de definirlo en menores de 13 años.

Las enfermedades que en los adultos provocan cansancio, en los niños a menudo se manifiestan por signos paradójicos. La falta de sueño y el efecto sedante del fenobarbital se traducen en falta de atención, hiperactividad y trastornos de la conducta. En cambio, numerosas afecciones pueden causar cansancio en los niños: infecciones y enfermedades degenerativas o tumorales del sistema nervioso central; trastornos genéticos del metabolismo; cuadros epilépticos, miopatías, neuropatías, alteraciones mitocondriales, perturbaciones psiquiátricas (depresión, ansiedad, somatización, fobia a la escuela, estrés y disfunción familiar).

Pliopys, a propósito de su desempeño en el Centro de Investigaciones sobre el Síndrome de Cansancio Crónico, ubicado en la Universidad de Illinois en Chicago, refiere que en un período de 3 años se evaluó a 300 pacientes remitidos con ese diagnóstico presunto. Entre ellos no había ningún niño y solo había seis adolescentes que no satisfacían los referidos criterios mayores y menores. Si bien es cierto que el diagnóstico de CFS en personas jóvenes no tiene carácter urgente, ya que no existe un tratamiento eficaz, en niños puede acarrear perjuicios, tales como: 1) postergación del diagnóstico de una enfermedad médica tratable; 2 ) retraso en la detección de estados poco frecuentes pero susceptibles al efecto de nuevos tratamientos, como el letargo en casos de déficit neurológicos crónicos y de síndrome de Rett; 3) enmascaramiento de problemas psicológicos o familiares que pueden causar cansancio; y 4) fomento de un estilo de vida inapropiado para el paciente, pero alentado por la familia en virtud de una presunta discapacidad física.
El diagnóstico en adolescentes requiere cautela. Recientemente ha sido objeto de atención la hipotensión de origen neurológico, que se asocia con cansancio. Se ha observado que esa alteración del sistema nervioso autónomo es responsable de 95\% de los casos atribuidos al CFS. De acuerdo a Fukuda et al., la mayoría de los pacientes que responden favorablemente al tratamiento con fludrocortisona, que es el indicado para ese tipo de hipotensión, son adolescentes. No obstante, muchos otros centros para el tratamiento de pacientes con CFS, incluido el de Chicago, no han podido duplicar sus resultados. Según Plioplys, ello obedece a la posibilidad de que adolescentes con una simple depleción de líquidos y electrólitos como causa determinante de cansancio secundario hayan recibido un diagnóstico erróneo de hipotensión de origen neural y por lo tanto se encuentren expuestos a las posibles complicaciones de un tratamiento prolongado con mineralocorticoides.

Dadas la incertidumbre y las dificultades asociadas con el diagnóstico de CFS en niños y adolescentes, es recomendable omitir esta entidad de la lista de enfermedades que pueden afectar a personas de esas edades. (Pliopys AV. Chronic fatigue syndrome should not be diagnosed in children. Pediatrics 1997;100:270-271).

\section{Características epidemiológicas de la conducta suicida en niños y adolescentes}

Tanto en México como en otros países, los suicidios en niños y adolescentes se han incrementado notablemente en las últimas décadas, según indican las estadísticas. Se trata, indudablemente, de un problema enfrentado con frecuencia por pediatras y médicos de servicios de urgencia, así como por expertos en salud mental (psiquiatras, psicólogos y trabajadores sociales).

Dado que los niños que intentan suicidarse suelen ser ingresados por los servicios de urgencia, Sauceda-García et al. llevaron a cabo una investigación en 21 pacientes atendidos consecutivamente durante 1995 en el Hospital de Pediatría del Centro Médico Nacional Siglo XXII, perteneciente al Instituto Mexicano del Seguro Social, en México, D.F. Los casos fueron estudiados clínicamente y con escalas psicométricas para determinar variables sociodemográficas, circunstancias del intento, métodos empleados y tipos de trastornos psicológicos, partiendo de la hipótesis de una preponderancia de la impulsividad en un trasfondo depresivo.

Se estudió a 21 pacientes entre las edades de 7 y 15 años, con un predominio de mujeres (razón de mujeres:hombres, 6:1) y de primogénitos. Los factores precipitantes más comunes fueron los conflictos 
familiares, que ocurrieron siempre en contextos de disfuncionalidad. Se trató de un primer intento en 13 pacientes y del segundo en los ocho restantes. Entre los métodos utilizados predominaron las intoxicaciones medicamentosas (con benzodiacepinas en primer término) y químicas (dos muertes se debieron a complicaciones tardías por ingestión de ácido muriático y de talio). De los 21 pacientes, 10 padecían de depresión, seis mostraban tendencias impulsivas y agresivas, y los cinco restantes tenían síntomas compatibles con dos o más diagnósticos psiquiátricos.

Las respuestas de los 20 progenitores que respondieron al interrogatorio revelaron que $17 \mathrm{pa}-$ cientes $(85 \%)$ tenían antecedentes de síntomas clínicos. Al aplicarse la prueba de ji cuadrado no se encontró ninguna diferencia estadísticamente significativa entre la depresión y la conducta impulsiva o agresiva como factor conducente al intento de suicidio, aunque fue mayor el número de pacientes deprimidos. En todos los pacientes se había estable- cido un diagnóstico psiquiátrico, lo cual confirma que el riesgo de suicidio en este grupo es 200 veces mayor que en la población en general.

Los autores concluyen que la determinación clínica de los estados depresivos e impulsivos subyacentes en pacientes que han intentado suicidarse tiene relevancia desde el punto de vista terapéutico, una vez que se hayan tratado las lesiones físicas provocadas por el método empleado. Aunque en todo niño o adolescente que intenta suicidarse se impone un tratamiento psicológico, los deprimidos graves pueden beneficiarse de la administración de fármacos antidepresivos, y los que sufren de impulsos agresivos, del uso de medicamentos psicoestimulantes o reguladores de la agresividad. (Sauceda-García JM, Montoya-Cabrera MA, Higuera-Romero FH, Maldonado-Durán JM, Anaya-Segura A, Escalante-Galindo P. Intento de suicidio en la niñez y la adolescencia: ¿síntoma de depresión o de impulsividad agresiva? Bol Med Hosp Infant Mex 1997;54:169-175).

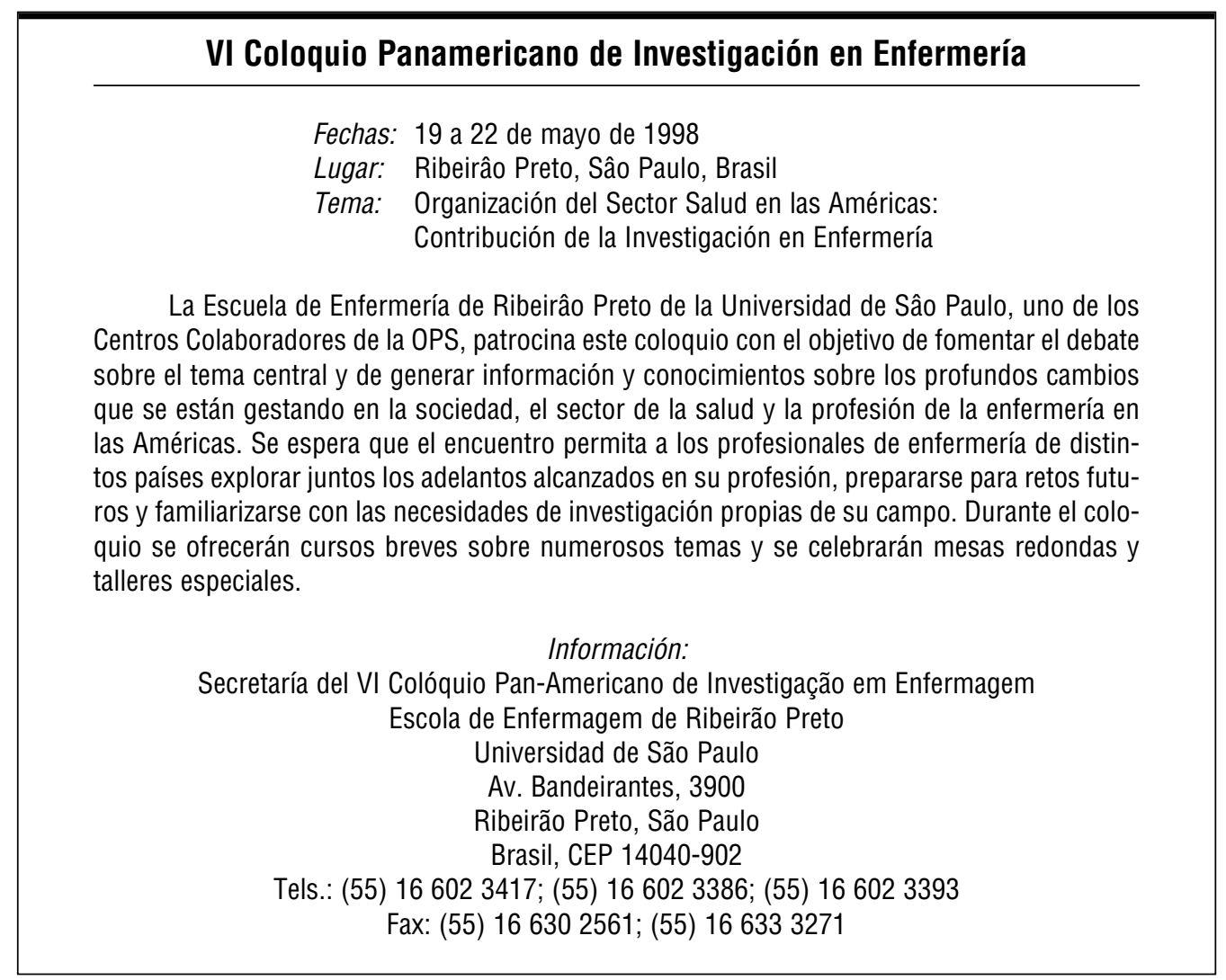

